\title{
Assessing the pre-REDD policies of countries with substantial forest area growth
}

\author{
Xin $\mathrm{Hu}^{{ }^{*}}$, Donald G. Hodges ${ }^{2}$ and Guoqing Shi ${ }^{1}$
}

\begin{abstract}
Hu, X., Hodges, D.G., Shi, G. 2014. Assessing the pre-REDD policies of countries with substantial forest area growth. - Forestry Studies | Metsanduslikud Uurimused 60, 34-43. ISSN 1406-9954. Journal homepage: http:// mi.emu.ee/forestry.studies
\end{abstract}

\begin{abstract}
Based on the method of Compensated Successful Efforts, this paper proposes a structural variables model to assess pre-REDD+ (Reducing Emission from Deforestation and Degradation plus) policies; selecting economic development, population growth, initial forest area, agricultural commodity export prices, and timber prices as structural variables, and empirically analyzes 11 high-forest-growth countries' policies from 1992 to 2011. Results show that the forest area growth rate was negatively correlated with the initial forest area and agricultural commodities export prices, and positively correlated with population density, GDP per capita, and timber export prices. China and India's entity fixed effects are more significant; in different periods the rate of actual forest area growth exceeded that of structural forest area growth in 11 countries. Overall, Compensated Successful Efforts proved to be useful for evaluating the effects of the high forest area growth country policies. Regardless, these countries should join REDD+ organizations and continue enhancing their forest management and increasing forest area. As part of this effort, REDD+ negotiations should consider fully compensation mechanisms for these countries to attract more countries and promote the progress of international climate negotiations.
\end{abstract}

Keywords: climate change, REDD+ mechanism, structural variables, policy assessment, Compensated Successful Efforts.

Authors' addresses: ${ }^{1}$ Hohai University, Nanjing, China; ${ }^{2}$ The University of Tennessee, Knoxville, TN 37996-4563, USA; *e-mail: Hu.Xin.1987@hotmail.com

\section{Introduction}

Tropical forests cover approximately $15 \%$ of the land surface (FAO, 2010), and store almost $25 \%$ of carbon found in the terrestrial biosphere (Bonan, 2008). Greenhouse gas emissions from deforestation and forest degradation have become the second major culprit in global warming, accounting for $12 \%-20 \%$ of total carbon emissions caused by anthropogenic factors (Sala et al., 2000; Houghton, 2008). Among countries with tropical forests, approximately 13 million hectares of forest were converted to other uses or lost through natural causes annually in the last decade (FAO, 2010).
Based on this, the United Nations Framework Convention on Climate Change (UNFCCC) introduced a low-cost mitigation mechanism in 2007 to aid developing countries in reducing deforestation and forest degradation, which was called "reducing emissions from deforestation and forest degradation (REDD)". The REDD+ strategies are an extended version of those of REDD, which signifies a stronger commitment that the 'co-benefits' of protecting biodiversity and livelihoods should be on par with carbon storage and uptake (Rosendal \& Andresen, 2011).

The REDD+ mechanism could provide financial compensation to participating countries capable of reducing emissions 
from deforestation (Scholz \& Schmidt, 2008). A variety of previous attempts to prevent deforestation have not achieved the desired effect; therefore the REDD+ mechanism provides a new framework, enabling countries to break away from the historical trend of deforestation. Although it has been favored by a number of nations and international environmental organizations in the post-Kyoto Protocol era, REDD+ has not yet become an internationally binding emissions reduction policy. One reason for this is the inherent flaws of forestry projects, such as additionally and permanence. Another critical factor is that REDD+ is not supported by developing countries with low deforestation rates. In its present form, REDD+ simply uses historical deforestation rates as the crucial determinant of compensation; therefore, it is developing countries with low deforestation rates have little incentive to participate in or support the program (Pirard \& Karsenty, 2009). In order to make more countries support REDD+, we propose a method of policy evaluation that distinguishes countries with high forest area growth rates from countries experiencing high rates of deforestation.

At present, little research focuses on evaluating REDD+'s ability to enable developing countries to protect their forests and reduce deforestation and degradation (Busch et al., 2009; Olander et al., 2008). This research concentrated almost exclusively on tropical countries with high deforestation rates. In addition, the pioneer projects launched by UN-REDD were implemented in countries with high-carbon values and high deforestation rates as well (Phelps et al., 2010). The assessment of REDD+ policies effects should be based on the differences between the observed level of deforestation (emission) and the predicted level of deforestation if REDD+ was not in place (the reference level). With advancing technology, measuring the actual level of future emissions will become more feasible (DeFries et al., 2007). The real difficulty lies in predicting the reference level of deforestation/emissions. Motel et al. proposed a new means of solving this problem by distinguishing between deforestation attributed to structural factors, market failures, and policy failures (Combes Motel et al., 2009). They used an econometric model to estimate the error between the observed deforestation rate and the structural deforestation rate as a means of assessing a country's forestry policies. However, this method focuses on countries with both high forest cover and high deforestation rates (HFHD). Consequently the structural variables they selected are not suitable for developing countries that have continued to increase forest cover.

The hypothesis of this research is that since countries with substantial forest area growth have implemented forest protection policies, their actual forest area growth rate should be higher than the structural forest area growth rate. If the hypothesis is true, these countries should be compensated by REDD mechanism for encouraging them to continue to implement forest conservation policies. Based on Motel's research (Combes Motel et al., 2009) this paper further develops the idea of Compensated Successful Efforts, extending the research to countries that continue to increase forest cover. This was accomplished by using forest area growth rate as the dependent variable; selecting economic development, population growth, initial forest area, agricultural commodity export prices, and timber export prices as exogenous structural variables; and providing a comparative analysis of 11 national preREDD+ era forest policies.

\section{Methods}

Deforestation and forest degradation are caused by a variety of reasons, but fundamentally they occur because those who convert or degrade forests benefit from the activities (Tacconi, 2009). The benefits 
typically are financial; higher initial returns can be realized, for example, from indiscriminate logging relative to sustainable forestry, leading to more land use/ cover change (LUCC). The Compensated Reductions (CR) approach proposes that developing countries that reduce their national emissions from deforestation below an agreed historical baseline will receive carbon certificates (Santilli et al., 2005). This method assumes that without the REDD framework, historical emission levels of greenhouse gases would continue to rise. Only when emissions fall below the historical baseline does a country receive carbon credits. However, while it is beneficial for some countries with high deforestation rates (such as Brazil and Indonesia), other countries that initiated activities to reduce deforestation and increase forest area early are at a disadvantage. If these countries are not rewarded for protecting the carbon stocks of the current forests, they are likely to pursue more profitable business projects and increase deforestation. Meanwhile, since the reference level is based on historical emissions levels, this method requires initial assessment and, due to a large number of unpredictable factors, its prediction value's reliability is often low.

Compared to Compensated Reduction, Compensated Successful Efforts (CSE) suggests that financial benefits should be provided on the basis of countries developing successful 'efforts' to reduce emissions from deforestation, which is an investment-based approach. This approach assumes that deforestation is due to structural factors and policy failures (Combes Motel et al., 2009). Therefore, this approach may have a better effect for any developing country that adopts a small policy correction. In the case in which all other conditions remain unchanged, for example, CSE enhances the effectiveness of using the correct protections and will greatly reduce tree felling (Culas, 2007). Meanwhile, if we already know the pertinent structural factors, then estimating deforestation from structural effects is much easier than estimating overall deforestation. The method can thus separate the causes of deforestation due to policies from structural factors and the value of the estimation is obtained a posteriori.

\section{Structural Variables Selected}

Using Compensated Successful Efforts to evaluate the policies of the REDD+ mechanism requires identifying structural variables that are related to forestation. Only when it is possible to distinguish the key structural variables can we accurately estimate the resultant forestation and thus assess the effectiveness of a country's REDD+ policies and determine if compensation is warranted. These structural variables are determined by long-term trends and external factors and are less affected by short-term governmental policies; that is, they are exogenous variables. The main structural variables behind forestation include economic development, population growth, initial forest area, agricultural commodity export prices, and timber export prices.

\section{Economic development}

The relationship between economic development and forestation is described by the Environmental Kuznets Curve (EKC). The relationship between forestation and income can be described by a U-shape: as income increases forestation first falls and later rises. In the case of increasing economies of scale, a country's economy changes its primary output from agriculture-based to industrial-based; a large percentage of forest land is used for agriculture and industry, and trees are processed into raw materials for industrial production. When an economy undergoes structural change, there is a strong tendency to shift from heavy industry to the service and technology sectors, leading to a downward trend in deforestation. As economic development continues, forest protection policies typically increase, and deforestation declines 
uninterrupted as reforestation increases. Therefore, the REDD+ mechanism should strive to compensate those governments that have adopted reforestation policies to increase forest area. In the model, per capita GDP will be used as a structural variable for economic development.

\section{Population growth}

The relationship between population growth and the growth in forest area is not clear. On the one hand, population increase may restrict forest area. As the population increases, the demand for food and residence also increases. Consequently, forest land is converted to agricultural or residential land. Conversely, the demand of wood products increases with rising populations, which lead to timber price increases. This is a positive incentive for forestation. In the model, population density will be used as a structural variable for population growth.

\section{Initial forest area}

Forest area growth is closely related to the initial forest area; the smaller the initial forest area, the higher the per unit cost of logging. Furthermore, when the initial forest area is relatively small, more non-forest land is available for establishing forest plantations. Forest area growth and initial forest area are negatively correlated and so many countries frequently follow the "forest scarcity path", where decreasing net forest loss is induced by increasing forest scarcity (Rudel et al., 2005). Moreover, the initial forest area as a structural variable is conducive to indirectly rewarding developing countries with early actions on forest conservation (UNFCCC, 2007). This is also consistent with the philosophy of REDD+: forest conservation, sustainable management, and the increase in forest carbon sequestration.

\section{Prices of agricultural exports}

Numerous studies reveal a positive correlation between agricultural prices and de- forestation (Angelsen \& Kaimowitz, 1999); higher prices increase the profitability of converting forest land to agricultural use. The reason for selecting export prices of agricultural products as structural variables is that export prices are mainly influenced by international commodity markets and less affected by domestic policy.

\section{Timber export prices}

Although the effect of higher international timber prices on deforestation is ambiguous and controversial (Arcand et al., 2008), it is beyond doubt that the export prices of timber are bound to have a profound impact on forest area growth. Higher prices might induce investment in logging operations and forest conversion to alternative land uses; conversely, higher prices might encourage sustainable forest management to improve the value of forests (Buys, 2007). Similar to agricultural exports, timber export prices are more influenced by international markets and less affected by domestic policy. Thus, in the model timber exports prices are employed as structural variables to examine the effect of forest products export prices on deforestation.

The selected variables are less affected by short-term government policies, and can be regarded as exogenous variables. Others factors, such as the level of foreign debt, and exchange rates are more obviously affected by a country's short-term policies (Angelsen \& Kaimowitz, 1999; Arcand et al., 2008), which are endogenous variables and should be regarded as under the realm of government policy rather than that of structural factors.

\section{Data Description}

The Global Forest Resources Assessment Report (FAO, 2010) categorized 100 nonAnnex I countries into four forest transition phases, based on the percentage of forest cover and rate of forest area growth/ decline in 2010. This paper focuses on countries in the fourth stage, where forest cover is less than $50 \%$ and the annual rate 
of change in forest area is greater than $0 \%$ for 2010. In order to ensure that the panel data are balanced, we excluded Cape Verde, Liberia, Rwanda and Swaziland as they are missing some data, and examined the remaining 11 developing countries (Table 1) to provide an empirical assessment of REDD+ policies.

Table 1. Research Objects.

\begin{tabular}{ll}
\hline Continent & Countries \\
\hline Africa & Cote d'Ivoire, Gambia \\
America & Chile, Costa Rica, Cuba, Uruguay \\
Asia & China, India, Philippines, Thailand, \\
& Vietnam \\
\hline
\end{tabular}

This empirical study selected 1992-2011 panel data from these 11 countries. Since the REDD+ mechanism was formally proposed in 2007 at the Bali conference, and furthermore, international organizations such as the FCPF and UN-REDD were established in 2008, the REDD+ mechanism has already officially entered its implementation stage. Therefore, this study focused on the "pre-REDD +" era of the 11 countries, assessing and analyzing the influence of their forest policies on forest area growth. Although the policies of the "pre-REDD+" era are not exactly the same as those of the REDD+ mechanism, it is undeniable that the design of the REDD+ mechanism originates from afforestation/ reforestation projects and the experiences of other types of forest protection policies (Angelsen \& Brockhaus, 2009; Pfaff et al., 2010). Therefore, the policies of the "preREDD+" era and the REDD+ mechanism are very similar in objectives, structure, and political/social content (Caplow et al., 2011).

Data for 1992-2011 on annual forest area growth rates, initial forest areas, agricultural commodities export prices and timber export prices were obtained from
FAOSTAT (www.faostat.fao.org). The export prices of agricultural commodities and timber were calculated by dividing the total value of the commodity exported by the total quantity exported. Population density and GDP per capita are from the World Bank (data.worldbank.org). Population density was calculated by dividing total population by land area. More detail is provided in Table 2 .

Table 2. Description of Variables.

\begin{tabular}{|c|c|c|}
\hline Variables & Description & Source \\
\hline \multicolumn{3}{|c|}{ Dependent variables } \\
\hline Forgrowth & $\begin{array}{l}\text { Annual forest area } \\
\text { growth rate, } \%\end{array}$ & FAO \\
\hline \multicolumn{3}{|c|}{ Explanatory variables } \\
\hline Forinitial & $\begin{array}{l}\text { Initial forest area, } \\
1000 \text { hectare }\end{array}$ & FAO \\
\hline GDPPC & $\begin{array}{l}\text { GDP per capita, } \\
\text { current US\$ }\end{array}$ & World Bank \\
\hline Popdensity & $\begin{array}{l}\text { Population density, } \\
\text { person } / \mathrm{km}^{2}\end{array}$ & World Bank \\
\hline Pagr & $\begin{array}{l}\text { Agricultural com- } \\
\text { modity export prices, } \\
\text { US\$/ton }\end{array}$ & FAO \\
\hline Ptim & $\begin{array}{l}\text { Timber export prices, } \\
\text { US } \$ / \mathrm{m}^{3}\end{array}$ & FAO \\
\hline
\end{tabular}

\section{Choice of Econometric model}

Before using panel data to estimate parameters, a suitable panel data model is needed to avoid errors in estimation. Panel data models include pooled, fixed effects, and random effects models. For selecting a panel data model, we first ran a Likelihood Ratio (F-test) to determine whether a pooled model or a fixed effects model was suitable, and then ran a Hausman test to decide between a random effects model and a fixed effects model. Using Eviews7.2 (EVIEWS.com) to conduct the F-test and Hausman test, the specific results are shown in Table 3 and Table 4. 
Table 3. Results of F-test.

\begin{tabular}{lccc}
\hline Effects Test & Statistic & d.f. & $p$-values \\
\hline $\begin{array}{l}\text { Cross-section } F \\
\text { Cross-section }\end{array}$ & 123.057505 & $(10,204)$ & 0.0000 \\
Chi-square & 429.110870 & 10 & 0.0000 \\
\hline
\end{tabular}

Table 4. Results of Hausman test.

\begin{tabular}{lccc}
\hline Hausman Test & $\begin{array}{c}\text { Chi-Sq. } \\
\text { Statistic }\end{array}$ & $\begin{array}{c}\text { Chi-Sq. } \\
\text { d.f. }\end{array}$ & $p$-values \\
\hline $\begin{array}{l}\text { Cross-section } \\
\text { random }\end{array}$ & 120.285097 & 5 & 0.0000 \\
\hline
\end{tabular}

According to the results of the F-test, the individual $p$-values all were less than 0.01 , therefore we rejected a pooled model and created a fixed effects model. Meanwhile the results of the Hausman test reveal that the individual $p$-values also averaged less than 0.01, indicating that a random effects model should be rejected in lieu of a fixed effects model. Therefore this paper used an entity fixed effects model to assess forest area growth. The model is given by the following equation:

$$
y_{i t}=c+c_{i}+\sum_{k=1}^{n} \beta_{k} \chi_{k i t}+\varepsilon_{i t}
$$

Where $i=1, \ldots, 11$ denotes the countries; $t=$ $1, \ldots, 20$ denotes the times periods; and $k=$ $1, \ldots, 5$ denotes the coefficients corresponding to the 5 structural variables (Table 2). Furthermore, $c$ is a constant, $c_{i}$ is the intercept term with respect to time for country $i$ (see below for more details), $\chi_{k i t}$ denotes the $k$ th structural variable for country $i$ at time $t, \beta_{k}$ is the regression variable for the $k$ th structural variable, and $\varepsilon_{i t}$ is the error term that is independently and identically distributed. Since structural variables are orthogonal to the error term, $\mathrm{E}\left(\varepsilon_{i t^{\prime}}, x_{k i t}\right)=0$ and $\forall k$ has a zero mean. This econometric model assumes that the present structural variables are correctly identified and the forest area growth rate does not affect the structural variables within time periods. $c_{i}$ contains all of a country's unobservable structural characteristics that are time period invariant, e.g. long-term climatic and geographical features. Consequently, the heterogeneity through space is assumed to be fully accounted for by the panel structure using the country fixed effects terms $c_{i}$.

Residuals were calculated as: $\hat{\varepsilon}_{i t} \equiv y_{i t}-\hat{y}_{i t}$ with $y_{i t}$ the observed forest area growth rate and $\hat{y}_{i t}$ the structural forest area growth rate. Residuals measure relative effects of policies to reduce deforestation or increase reforestation. If residuals are significantly positive, it indicates that the REDD+ policies effectively reduce deforestation or increase forestation and if residuals are negligibly small or negative, it suggests that the REDD+ policies have failed. Residuals apparently also include the measurement error of forestation rates and idiosyncratic shocks of orthogonal explanatory variables. Hence, only residuals that are significantly non-zero can be used to reflect upon the effects of REDD+ policies.

\section{Results and Discussion}

The results are shown in Table 5. The empirical results reveal that all structural variables were significant at the $5 \%$ level, implying that the choice of model is suitable and effective. The estimated $R^{2}$ value indicates that the structural variables explains $87 \%$ of the growth in forest area.

In this model, the coefficient $\beta_{k}$ corresponding to initial forest area is negative, indicating that the original forest area is negatively correlated with forest area growth. The estimated coefficient implies that if country I's initial forest area is larger than country II's by $1 \%$, then country I's forest area growth rate will lower than country II's by $5.97 \%$. The coefficient for GDP per capita is positive, which is in line with the Environmental Kuznets Curve 
Table 5. Estimation results.

\begin{tabular}{|c|c|c|c|c|c|}
\hline Variable & Coefficient & & t-Statistic & \multicolumn{2}{|c|}{$p$-values } \\
\hline C & 46.85554 & & 11.44807 & \multicolumn{2}{|c|}{0.0000} \\
\hline LOG(Forinitial) & -5.970919 & & -12.13672 & \multicolumn{2}{|c|}{$0.0000^{* *}$} \\
\hline LOG(GDPPC) & 0.583271 & & 6.037147 & \multicolumn{2}{|c|}{$0.0000^{* *}$} \\
\hline LOG(Pagr) & -0.447763 & & -3.870711 & \multicolumn{2}{|c|}{$0.0001^{* *}$} \\
\hline LOG(Ptim) & 0.068621 & & 1.993057 & \multicolumn{2}{|c|}{$0.0476^{*}$} \\
\hline LOG(Popdensity) & 1.338968 & & 4.023244 & \multicolumn{2}{|c|}{$0.0001^{* *}$} \\
\hline \multicolumn{6}{|l|}{ Fixed Effects (Cross) } \\
\hline $\mathrm{CHL}-\mathrm{C}$ & 4.774781 & $\mathrm{CHN}-\mathrm{C}$ & 18.75792 & CRI-C & -8.371075 \\
\hline CIV-C & 1.960642 & CUB-C & -7.221452 & GMB-C & -17.77250 \\
\hline IND-C & 10.61003 & $\mathrm{PHL}-\mathrm{C}$ & -2.409008 & THA-C & 3.355141 \\
\hline URY-C & -6.705678 & VNM-C & 3.021199 & & \\
\hline R-squared & 0.879985 & & & & \\
\hline Adjusted R-squared & 0.871161 & & & & \\
\hline
\end{tabular}

**Significant at the $1 \%$ level; *Significant at the $5 \%$ level

(EKC) describing an inverted " $U$ "-shaped relationship between income and deforestation. The 11 countries are already on the right side of the EKC curve, therefore, with income increasing, deforestation is declining and reforestation is increasing. In particular, with GDP per capita increasing by $1 \%$, the forest area will rise by $0.58 \%$.

Population density is positively correlated with forest area growth, mainly due to strengthening government policy and increasing awareness of environmental protection in these countries encouraging forestation activities. The coefficient of agricultural commodity export prices is negative, indicating that if agricultural export prices rise by $\$ 100$ per ton, the forest area growth rate will be reduced by $44.78 \%$. Therefore, rising exports prices of agricultural commodities stimulate the development of domestic agriculture, leading to deforestation. The coefficient corresponding to timber export prices is positive, which suggests that an increase in export prices leads to sustainable forest manage- ment over deforestation, but the impact is relatively small.

Of the 11 countries examined, the constants corresponding to fixed effects for Chile, China, Cote d'Ivoire, India, Thailand, and Vietnam are positive. This indicates that the individual fixed effects of these six countries are more significant, and therefore, they rank higher on the list of forest area growth rates. Specifically, they are in a stage of positive forest area growth. The other five countries are still in a stage of deforestation, especially Gambia.

Separate analyses of the 11 nations' preREDD+ era forest policy effects (Figure 1) reveal that when the actual forestation rate exceeds the structural forestation rate, domestic policies have played an effective role in promoting forest area growth, and thus the REDD+ mechanism should compensate for this. If this is not the case, then it cannot be compensated.

From 2001 to 2011, the actual forestation rates of China and Costa Rica are higher than the rate of structural forestation. Re- 
viewing both countries' domestic policies we find that: (1) the Chinese government began to change environmental awareness and pay more attention to forests since a rare flood in 1998. China adopted a series of policies and measures, such as Natural Forest Protection Program (NFPP), and has made remarkable achievements in protecting forest resources and increasing forest coverage. (2) Costa Rica initiated a conservation program in the late 1990s on Payments for Environment Services to avoid deforestation. Therefore, forest area growth is due in part to the two countries' policies, and they should be compensated by the REDD+ mechanism. A similar situation also occurred in Chile and Vietnam between 1992 to 2004. The two countries implemented policies to encourage afforestation in the 1990s. However, as pressures from domestic demand and timber exports increased, Chile and Vietnam's actual forest area growth rate became less than the structural rate after 2005.

Through the panel model, we can determine the difference between the actual forestation rate and structural forestation rate in different stages by country. In order to determine whether a nation should be compensated by REDD+, we also need to analyze the domestic policies to ascertain whether forest area growth results from policy implementation. However, when the actual forest area rate is lower than the structural rate, policies may be impacted by market factors and do not play a role. Thus, this approach can be improved by more strict independent variables.

\section{Conclusions}

If we cannot effectively reduce deforestation and increase forestation in the postKyoto Protocol era, mitigating global climate change will be almost impossible. Through the analysis and discussion of these results, the following conclusions can be drawn from this study:
In the design of REDD+ policies and payment mechanisms, methods to calculate and examine emission reductions should utilize Compensated Successful Efforts rather than Compensated Reduction. By examining historical baselines, Compensated Reduction measures the reduction in emissions over a fixed period of time to provide carbon emission credits, which is favorable for countries with a high deforestation rate. For other countries like China that took actions early actions to reduce deforestation and increase forest area, however, the effect is counterproductive. If the REDD+ mechanism is confined to high deforestation rate countries, it is likely to become a disincentive for countries with high-growth forests and low deforestation rates, causing more deforestation. However, if the compensation is based on a country's efforts to reduce deforestation, the developing countries with high forest area growth can increase their efforts and push the actual forest area growth rate above the structural rate. Thus, they can receive more compensation from the existing voluntarily fund-based REDD+ mechanism (Pirard et al., 2009). Meanwhile, the method of Compensated Successful Efforts can be used to attract developing countries with high forest cover and low deforestation rates to REDD+, and promote international negotiations for mitigating climate change.

Developing countries with high forest area growth and low deforestation rates should implement REDD+ as soon as possible. Implementation of REDD+ can effectively reduce $\mathrm{CO}_{2}$ emissions from deforestation, and at a lower cost than that for industrial emissions reductions. Therefore, REDD+ will, from both a technological and economic standpoint, be one of the most important measures to mitigate climate change. By the end of 2013, UN-REDD already included 49 member states; the Forest Carbon Partnership Facility also has 44 member states and organizations. Of the 11 countries in this study, Chile, Costa Rica, Cote d'lvoire, the Philippines, Thailand, 

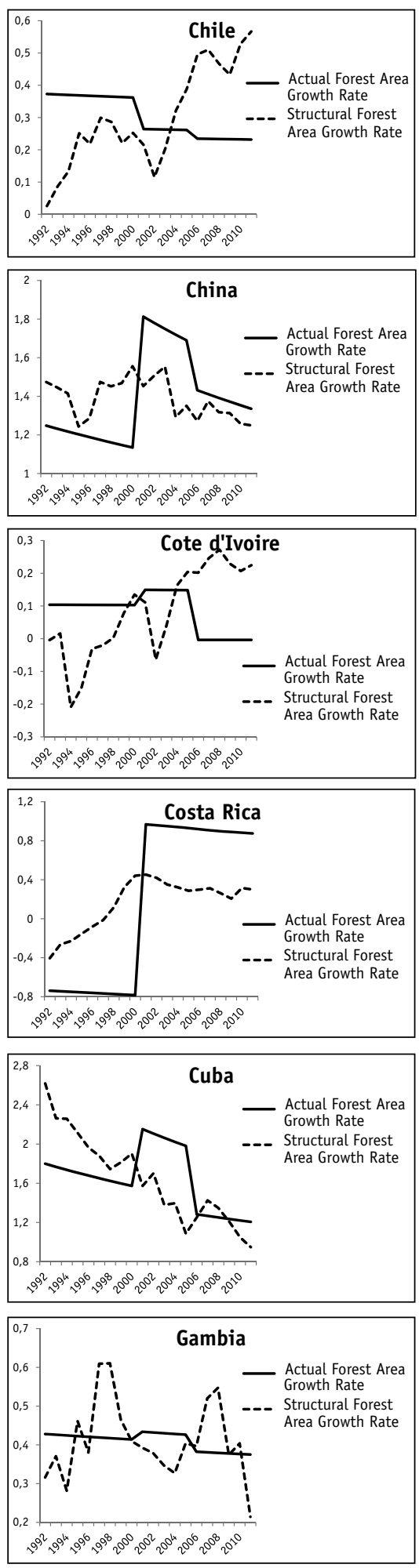
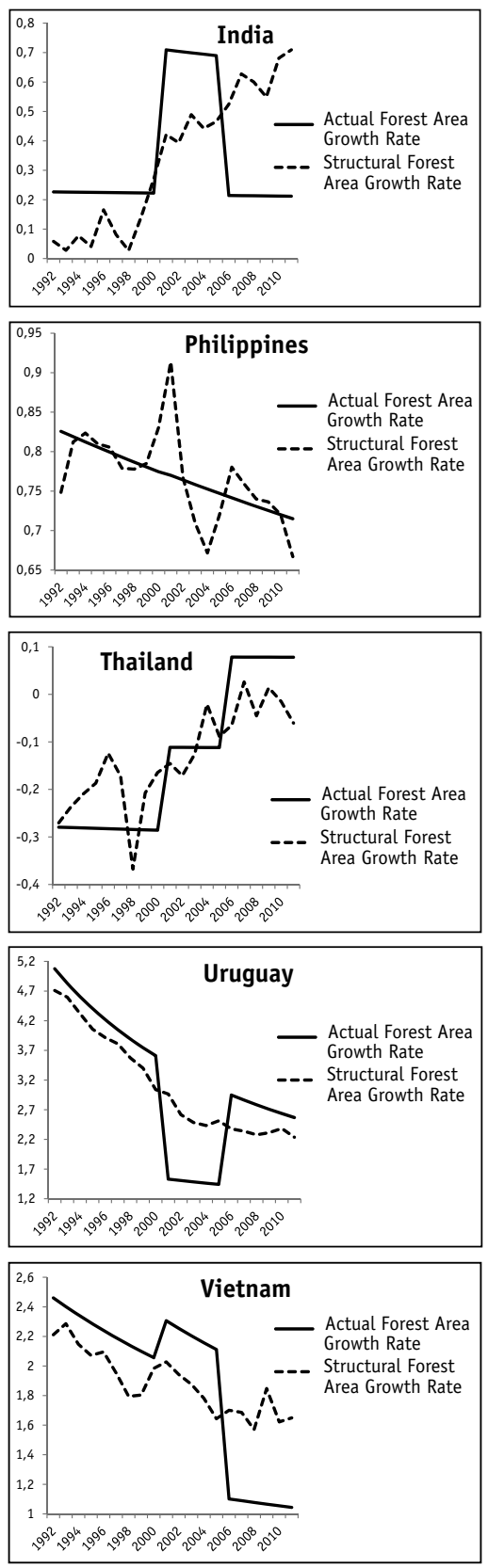

Figure 1. Actual forest area growth rate and structural forest area growth rate by country. 
Vietnam, and Uruguay, have or are preparing to join the REDD+ scheme. However, large developing countries such as China and India, have not yet joined any of REDD+'s international organizations, nor has any REDD+ project occurred in these countries. Although these countries have entered the fourth stage of forest change, their economies are still developing. Early implementation of REDD+ can help them grasp the opportunities, reduce the costs of cutting emissions, and obtain more revenue.

\section{References}

Angelsen, A., Brockhaus, M. 2009. Realising REDD+: National strategy and policy options. CIFOR.

Angelsen, A., Kaimowitz, D. 1999. Rethinking the causes of deforestation: lessons from economic models. - The World Bank Research Observer, 14, 73-98.

Arcand, J.-L., Guillaumont, P., Jeanneney, S.G. 2008. Deforestation and the real exchange rate. - Journal of Development Economics, 86, 242-262.

Bonan, G.B. 2008. Forests and climate change: forcings, feedbacks, and the climate benefits of forests. - Science, 320, 1444-1449.

Busch, J., Strassburg, B., Cattaneo, A., Lubowski, R., Bruner, A., Rice, R., Creed, A., Ashton, R., Boltz, F. 2009. Comparing climate and cost impacts of reference levels for reducing emissions from deforestation. - Environmental Research Letters, 4, 044006

Buys, P. 2007. At loggerheads?: agricultural expansion, poverty reduction, and environment in the tropical forests. World Bank Publications.

Caplow, S., Jagger, P., Lawlor, K., Sills, E. 2011. Evaluating land use and livelihood impacts of early forest carbon projects: Lessons for learning about REDD+. - Environmental Science \& Policy, 14, 152-167.

Combes Motel, P., Pirard, R., Combes, J.-L. 2009. A methodology to estimate impacts of domestic policies on deforestation: Compensated Successful Efforts for "avoided deforestation" (REDD). Ecological Economics, 68, 680-691.

Culas, R.J. 2007. Deforestation and the environmental Kuznets curve: An institutional perspective. Ecological Economics, 61, 429-437.

DeFries, R., Achard, F., Brown, S., Herold, M., Murdiyarso, D., Schlamadinger, B. 2007. Earth observations for estimating greenhouse gas emissions from deforestation in developing countries. - Environmental Science \& Policy, 10, 385-394.
FAO. 2010. Global Forest Resources Assessment 2010 Main Report. FAO, Rome.

Houghton, R. 2008. Carbon flux to the atmosphere from land use changes 1850-2005. TRENDS: a compendium of data on global change. Carbon Dioxide Information Analysis Center, Oak Ridge National Laboratory, US Department of Energy, Oak Ridge. cdiac. ornl. gov/trends/landuse/ houghton/houghton. htmlS.

Olander, L.P., Gibbs, H.K., Steininger, M., Swenson, J.J., Murray, B.C. 2008. Reference scenarios for deforestation and forest degradation in support of REDD: a review of data and methods. - Environmental Research Letters, 3, 025011.

Pfaff, A., Sills, E.O., Amacher, G.S., Coren, M.J., Lawlor, K., Streck, C. 2010. Policy impacts on deforestation. Lessons learned from past experiences to inform new initiatives. Duke Nicolas Institute for Environmental Policy Solutions, NI R 10-02. $55 \mathrm{pp}$.

Phelps, J., Guerrero, M., Dalabajan, D., Young, B., Webb, E. 2010. What makes a 'REDD'country? Global Environmental Change, 20, 322-332.

Pirard, R., Combes, J.-L., Combes Motel, P. 2009. A response to the commentary on "Compensated Successful Efforts". - Ecological Economics, 68, 2179-2181.

Pirard, R., Karsenty, A. 2009. Climate change mitigation: should "avoided deforestation" be rewarded? - Journal of Sustainable Forestry, 28, 434-455.

Rosendal, G.K., Andresen, S. 2011. Institutional design for improved forest governance through REDD: Lessons from the global environment facility. - Ecological Economics, 70, 1908-1915.

Rudel, T.K., Coomes, O.T., Moran, E., Achard, F., Angelsen, A., Xu, J., Lambin, E. 2005. Forest transitions: towards a global understanding of land use change. - Global Environmental Change, 15, 23-31.

Sala, O.E., Chapin, F.S., Armesto, J.J., Berlow, E., Bloomfield, J., Dirzo, R., Huber-Sanwald, E., Huenneke, L.F., Jackson, R.B., Kinzig, A. 2000. Global biodiversity scenarios for the year 2100. Science, 287, 1770-1774.

Santilli, M., Moutinho, P., Schwartzman, S., Nepstad, D., Curran, L., Nobre, C. 2005. Tropical deforestation and the Kyoto Protocol. - Climatic Change, 71, 267-276.

Scholz, I., Schmidt, L. 2008. Reducing emissions from deforestation and forest degradation in developing countries: meeting the main challenges ahead. Deutsches Institut für Entwicklungspolitik.

Tacconi, L. 2009. Compensated successful efforts for avoided deforestation vs compensated reductions. - Ecological Economics, 68, 2469-2472.

UNFCCC. 2007. Report on the Second Workshop on Reducing Emissions from Deforestation in Developing Countries. UNFCCC, Bonn, Germany. 